\title{
Autonomia para quem? O discurso médico hegemônico sobre a violência obstétrica no Brasil*
}

\author{
Luciana Aparecida Palharini**
}

\section{Resumo}

A violência obstétrica é considerada atualmente e de acordo com a Organização Mundial da Saúde um problema de saúde pública. No Brasil, apesar de pesquisas recentes, órgãos públicos $e$ movimentos sociais de mulheres denunciarem uma situação grave, o tema tem sido abordado pelo discurso médico hegemônico com grande resistência em enfrentar o debate de fato e propor mudanças na assistência ao parto. O objetivo desta pesquisa foi a investigação do posicionamento dos órgãos da classe profissional médica sobre os debates atuais da violência obstétrica, a partir da análise do discurso em textos veiculados por essas instituições.

Palavras-chave: Violência Obstétrica, Gênero, Direitos Sexuais e Reprodutivos das Mulheres, Autonomia da Mulher no Parto, Discurso Médico Hegemônico.

* Recebido em 23 de março de 2016, aceito em 26 de janeiro de 2017.

** Colaboradora no Programa de Pós-graduação Multiunidades em Ensino de Ciencias e Matemática (PECIM), Unicamp, Campinas, SP, Brasil. luapalharini@gmail.com 
Autonomy for Whom? The Medical Hegemonic Discourse about Obstetric Violence in Brazil

\begin{abstract}
Obstetric violence is currently considered a public health problem according to the World Health Organization. In Brazil, although recent researches, public agencies and women's social movements have reported a serious situation, the theme has been approached by the hegemonic medical discourse with great resistance in truly facing the debate to propose changes in childbirth care. This research aimed to investigate the position of medical professional bodies about the current debates on obstetric violence through the analysis of the discourse in texts published by these institutions
\end{abstract}

Keywords: Obstetric Violence, Gender, Women's Sexual and Reproductive Rights, Women's Autonomy in Childbirth, Hegemonic Medical Discourse. 


\section{Introdução}

Desde os anos 1980, o modelo obstétrico brasileiro tem sido questionado por pesquisadores e especialistas da área da saúde e por movimentos sociais pela humanização do parto e nascimento, que, ancorados nos estudos baseados em evidências científicas e no diálogo com agências de saúde governamentais (Tornquist, 2002), têm problematizado os modos de intervenção desse "modelo tecnocrático" (Davis-Floyd, 1992) na Obstetrícia. Em linhas gerais, a centralidade da crítica que se faz ao modelo hegemônico de atenção ao parto e nascimento englobam as questões: da gestação e do parto atendidos sob o enfoque patológico, eliminando-se as esferas sociais, culturais e existenciais; da perda do protagonismo da mulher nesses eventos; do abuso de procedimentos artificiais; e da violação de direitos humanos $e$ sexuais e reprodutivos das mulheres (Diniz, 2009, 2001; Diniz; Chacham, 2006; Torquinst, 2002).

O parto no Brasil teria assumido um significado patológico com foco na dor como uma experiência traumática e na cirurgia cesariana como o "padrão ouro da assistência obstétrica brasileira" (Ferreira Jr.; Barros, 2011). A inadequação e a realização de procedimentos rotineiros não recomendados por órgãos internacionais como a Organização Mundial da Saúde (OMS) têm sido denunciadas com frequência nos últimos anos. As elevadas taxas de cirurgia cesariana ${ }^{1}$, principalmente na rede suplementar e privada, que têm colocado o Brasil por anos seguidos como líder no ranking mundial dessa prática obstétrica, continua sendo

1 A taxa média de cesarianas no país cresceu de $38 \%$, em 2000 , para $52 \%$ em 2010, mantendo-se esse índice até 2014, e colocando o Brasil como recordista desse tipo de parto no cenário obstétrico mundial. Essa média ainda difere em relação a diversas variáveis, entre elas o tipo de serviço de atendimento ao parto. No setor público, a média desse tipo de parto é de $46 \%$; nas redes suplementar e privada, a média é de $88 \%$, variando de $80 \%$ a $100 \%$ em algumas maternidades privadas do país. Fonte: Pesquisa Nascer no Brasil: inquérito nacional sobre parto e nascimento, coordenada pela Fiocruz, cujas informações e principais resultados estão disponíveis em: http://www6.ensp.fiocruz.br/nascerbrasil/ _ acesso em: 17 maio 2015. 
motivo de preocupação de órgãos públicos. Muitos desses números se devem a cesáreas desnecessárias e sem indicações médicas (Domingues et al., 2014).

$\mathrm{O}$ problema não tem sido apontado apenas em relação às vantagens de cesárea ou parto normal. Essa demanda pela cesárea tem sido pontuada também como uma demanda por dignidade, já que o modelo de parto "normal" típico tem sido definido como intervencionista e traumático (Maia, 2010). Os pressupostos de gênero que conduzem a assistência no Brasil se expressam na superestimação dos benefícios da tecnologia e na subestimação ou negação dos desconfortos e efeitos adversos das intervenções, de acordo com Diniz (2009). Um modelo que, segundo a autora, estaria contribuindo para uma "pessimização do parto" como meio instrumental para favorecer a cesariana de rotina.

O discurso biomédico hegemônico, por outro lado, centra seus argumentos na noção de risco do parto vaginal e na justificativa do excesso de procedimentos como necessários à boa prática obstétrica.

Contudo, no que diz respeito ao discurso do movimento pela humanização do parto e nascimento, cabe mencionar que a noção de risco também se constitui como argumento importante, à medida que dados de morbimortalidade materna e neonatal associados à cesariana desnecessária e a outras intervenções obstétricas - que culminam, muitas vezes, em uma cesárea desnecessária - também têm sido mobilizados para criticar o modelo hegemônico de assistência (Diniz, 2009). Para a autora, o debate sobre a qualidade da assistência obstétrica no Brasil recai, muitas vezes, na polaridade entre parto normal e parto cesáreo, o que seria um equívoco, já que, diante das evidências, ninguém defenderia que a cesariana sem indicações médicas não tenha resultados inferiores ao parto fisiológico. Mas, "quando comparado ao parto vaginal repleto de intervenções desnecessárias, dolorosas e potencialmente danosas, pode parecer uma alternativa comparável", comparação essa que não seria 
honesta e nem cientificamente aceitável (Diniz, 2009:321). Ainda, segundo Diniz (2009:320):

No Brasil, além do parto espontâneo ser percebido pelos profissionais como mais arriscado para o bebê, também é tido como mais arriscado para a própria mãe, sendo associado a danos sexuais irreversíveis. Os profissionais praticam intervenções sobre a vagina, como a episiotomia (que é uma laceração de $2^{\circ}$ grau, no mínimo) e os fórceps, que aumentam os riscos de danos genitais graves, e quando estes danos ocorrem, responsabilizam o parto em si pelos danos. Desta forma, o dano iatrogênico é invisibilizado e redescrito como um dano "natural" do parto, associado ao processo fisiológico e não às intervenções.

\section{Violência obstétrica}

A violência nos processos de gestação, parto e pós-parto tem sido alvo de denúncias e reflexão pelos movimentos feministas desde os anos 1980, mas foi principalmente a partir do início dos anos 2000 que esse debate atingiu uma efervescência no meio acadêmico, nos órgãos governamentais e nas redes sociais no Brasil (Sena; Tesser, 2017), sendo ainda um tema incipiente e permeado por imprecisões. Em artigo recente, Diniz et al. (2015) realizaram um mapeamento do conceito de violência obstétrica, assim como de suas definições, possíveis causalidades e impactos sobre a saúde materna. As autoras identificam um conjunto de definições de violência obstétrica que tem sido proposto desde os anos 1980. Uma das definições é baseada na adotada pela Venezuela - país pioneiro na América Latina em tipificar essa forma de violência, em 2007 -, oferecida aqui como suporte para melhor entendimento sobre o tema:

Entende-se por violência obstétrica a apropriação do corpo e dos processos reprodutivos das mulheres por profissional de saúde que se expresse por meio de relações desumanizadoras, de abuso de medicalização e de patologização dos processos naturais, resultando em perda 
de autonomia e capacidade de decidir livremente sobre seu corpo e sexualidade, impactando negativamente na qualidade de vida das mulheres (Tesser et al., 2015:30).

Os indícios de maus tratos identificados em diversos países, em particular em países em desenvolvimento, levaram as pesquisadoras D'Oliveira et al., em artigo publicado na revista The Lancet, em 2002, a concluírem que a violência cometida por profissionais em maternidades afeta o acesso e a qualidade de serviços, repercutindo sobre sua efetividade $e$ a adesão das pacientes, bem como na ocorrência de mortalidade maternoinfantil.

No Brasil, uma pesquisa divulgada em 2010, conhecida pelo título Na hora de fazer não gritou, mostra uma situação preocupante: uma em cada quatro mulheres brasileiras já sofreram violência no parto. A pesquisa, que faz parte de uma investigação mais ampla intitulada Mulheres brasileiras e gênero nos espaços público e privado (Venturi; Godinho, 2010), coordenada pela Fundação Perseu Abramo em parceria com o Serviço Social do Comércio (SESC), ficou conhecida por esse nome pela ampla divulgação realizada na internet, especialmente pelo sítio eletrônico da Agência de Reportagem e Jornalismo Investigativo. ${ }^{2}$ "Na hora de fazer não gritou" é a segunda frase mais ouvida pelas mulheres (14\%). A primeira é "Não chora, não, que ano que vem você está aqui de novo" (15\%). Ao todo, $23 \%$ das mulheres entrevistadas ouviram algum despropósito durante o parto. Os tipos de violência identificados variam desde verbal à violência física, incluindo procedimentos médicos de rotina não recomendados por pesquisas recentes e pela própria OMS (WHO, $1985)^{3}$, além de violência de cunho sexual.

2 Cf. http://apublica.org/2013/03/na-hora-de-fazer-nao-gritou/, acesso em $12 \mathrm{dez}$. 2016.

3 Algumas das condutas e dos procedimentos identificados como violência obstétrica (adaptado de Tesser et al., 2015): procedimentos sem justificativa clínica e intervenções "didáticas", como toques vaginais dolorosos e repetitivos; cesáreas e episiotomias desnecessárias; imobilização física em posições dolorosas; 
É importante destacar que diversos autores (Diniz et al., 2016; Hotimsky et al., 2013; Aguiar, 2010; Santos; Shimo, 2008; Diniz, 2001) têm mostrado que esse tipo de violência não ocorre devido a equipes ou indivíduos mal treinados e nem se configuram como exceções de comportamentos. Trata-se, na maioria das vezes, da realização de procedimentos que compõem o protocolo comum de serviços de assistência obstétrica no Brasil, muitos deles em hospitais-escola.

Por esse motivo, a violência obstétrica tem sido identificada como uma violência institucional e de gênero, que faz parte da cultura médica hegemônica acerca do parto. As situações reveladas pelas pesquisas implicam violações de direitos humanos e direitos sexuais e reprodutivos das mulheres. A relevância do tema e sua gravidade foi confirmada recentemente por uma publicação da Organização Mundial da Saúde (WHO, 2014), que o reconhece como um problema de Saúde Pública, propondo recomendações para que governos $e$ instituições de pesquisa

prática da episiotomia e outras intervenções sem anestesia, sob a crença de que a paciente "já está sentindo dor mesmo"; realização da episiotomia em mulheres que verbalmente ou por escrito não autorizaram essa intervenção; desrespeito ou desconsideração do plano de parto; indução à cesárea por motivos duvidosos; não informação dos danos potenciais de longo prazo para os nascidos por cesariana; ambiente de maternidade que mantém enfermarias de trabalho de parto coletivas, sem biombo separando os leitos, e que ainda alegam falta de privacidade para justificar o desrespeito ao direito a acompanhante; formas de comunicação desrespeitosas com as mulheres, subestimando e ridicularizando sua dor, desmoralizando seus pedidos de ajuda; humilhações de caráter sexual, do tipo "quando você fez você achou bom, agora está aí chorando"; tratamento diferencial com base em atributos considerados positivos (casada, com gravidez planejada, adulta, branca, mais escolarizada, de classe média, saudável, etc.), depreciando as que têm atributos considerados negativos (pobre, não escolarizada, mais jovem, negra) ou que questionam ordens médicas; abandono, negligência ou recusa de assistência às mulheres que são percebidas como muito queixosas ou nos casos de aborto incompleto; retenção de pacientes até que saldem as dívidas com os serviços; no Brasil e em outros países, surgem relatos de detenções policiais de parturientes; descumprimento da Lei do Acompanhante (Lei n ${ }^{\circ} 11.108$, de 07/04/2005). 
possam dar visibilidade a esse tipo de violência, bem como promover sua prevenção.

Em 2012, a Rede Parto do Princípio elaborou um dossiê sobre a violência obstétrica no Brasil, para a Comissão Parlamentar Mista de Inquérito (CPMI) da Violência contra as Mulheres. ${ }^{4}$ Uma cartilha destinada à divulgação para as brasileiras também foi publicada pela Rede em parceria com o Fórum de Mulheres, em 2014. ${ }^{5}$ Nos últimos anos, a violência obstétrica tem sido denunciada por diversas mulheres aos Ministérios Públicos Federal e estaduais.

A violência obstétrica contra a mulher, forma ainda pouco
conhecida e debatida, que é perpetrada por profissionais
que deveriam proteger e cuidar da saúde física e mental das
parturientes: médicos, enfermeiros e auxiliares de
enfermagem. Caracterizada por ocorrer num dos momentos
de maior vulnerabilidade da vida de qualquer mulher, essa
violência se materializa como negligência, violência verbal
(grosserias, ameaças e humilhações intencionais), violência
física (incluindo a não utilização de analgesia quando
necessário e a realização de cirurgias desnecessárias e
indesejadas), além do abuso sexual (Relatório Final da
Comissão Parlamentar Mista de Inquérito da Violência Contra as
Mulheres do Senado Federal, 2013).

Outra atuação importante sobre o tema tem sido realizada por movimentos sociais de mulheres, especialmente ligados à causa da humanização do parto. A internet tem se tornado um espaço de militância da cena obstétrica por mulheres engajadas em movimentos feministas e/ou da área da saúde. Duas experiências que merecem destaque pela abrangência $e$

4 Disponível em:

http://www.senado.gov.br/comissoes/documentos/SSCEPI/DOC\%20VCM\%2036 7.pdf, acesso em: 13 dez. 2014.

5 Disponível em:

http://media.wix.com/ugd/2a51ae a3a1de1e478b4a8c8127273673074191.pdf, acesso em: 14 dez. 2014. 
repercussão que tiveram são: (1) o Teste da Violência Obstétrica, promovido por duas blogueiras e ativistas pela humanização do parto nas redes sociais e que resultou na coleta de 1.966 relatos de nascimentos em 38 dias; e (2) a produção do documentário Violência obstétrica - a voz das brasileiras, que partiu da proposta de convidar mulheres que haviam sofrido violência no parto a enviarem um vídeo caseiro relatando suas experiências. $\mathrm{O}$ documentário, que reúne mais de vinte vídeos e foi amplamente divulgado em sites, redes sociais e blogs, também foi apresentado em congressos científicos, recebendo o título de melhor documentário apresentado no Seminário Internacional Fazendo Gênero, em 2013, pelo júri popular. ${ }^{6}$ Essas pesquisas, realizadas informalmente, contribuíram de forma significativa para a visibilidade do tema e o engajamento de diferentes setores coletivos, pela abrangência que proporcionam as redes sociais $e$ blogs na comunicação via internet.

Há, portanto, uma efervescência do tema da violência obstétrica atualmente, que tem gerado conflitos na cena política do parto, na medida em que o modelo hegemônico de assistência tem sido questionado a partir da questão técnico-científica de suas práticas, além dos maus-tratos denunciados em maternidades $e$ hospitais do país e associados a uma cultura médica autoritária. As denúncias de movimentos sociais ao lado de dados divulgados por pesquisas científicas e a realização de audiências públicas em todo o país revelam uma situação grave.

Por outro lado, a percepção de que o discurso médico hegemônico tem encarado esse momento ainda com grande resistência (Diniz, 2016) é notória. A fim de buscar como os órgãos representativos da classe profissional médica se posicionam acerca dos debates atuais, especialmente sobre a violência obstétrica no Brasil, o objetivo deste trabalho foi analisar o discurso presente em publicações veiculadas por esses órgãos. O recorte para o tema da

\footnotetext{
${ }^{6}$ Os detalhes dessas pesquisas e seus resultados podem ser consultados na publicação de Sena e Tesser (2017).
} 
violência obstétrica se deu por razões que serão explicitadas na seção seguinte.

\section{Fonte dos dados e referenciais para análise}

A investigação inicial da pesquisa se deu por meio da busca de temas gerais relacionados a discussões recentes sobre a assistência obstétrica brasileira, a partir de alguns descritores ${ }^{7}$, em sítios eletrônicos de órgãos representativos da classe profissional médica. Foram analisados 58 textos, entre artigos de opinião, notícias, notas, recomendações, debates, manuais e entrevistas, publicados entre 2011 e 2016 - com exceção de um debate sobre um tema específico, de 2004. A partir de alguns temas encontrados $^{8}$ e a partir das razões que se seguem, foram selecionados 10 textos sobre o tema da violência obstétrica para análise específica neste trabalho: (1) a frequência com que o tema foi encontrado em publicações recentes dos órgãos representativos; (2) tem sido motivo de polêmicas nos últimos anos, principalmente por envolver procedimentos arraigados na cultura médica obstétrica no Brasil, como a episiotomia; e (3) a relevância do tema na atualidade e em consonância com os referenciais da pesquisa.

7 Os descritores utilizados foram: humanização do parto; parto humanizado; parto normal; cesárea; cesariana; parto domiciliar; casas de parto; centros de parto normal; violência obstétrica; violência no parto; violência de gênero no parto; violência institucional no parto; parto seguro. Este último descritor foi incorporado posteriormente, a partir do que foi encontrado nos textos, em que alguns médicos propõem a substituição do termo "violência obstétrica" por "parto seguro".

8 Os temas encontrados foram: cesárea a pedido; violência obstétrica; parto domiciliar; parto humanizado; humanização do parto; Centros de Parto Normal (CPN); Resolução $n^{\circ}$ 368/2015 (sobre a regulação da assistência obstétrica na rede suplementar, com medidas que visam diminuir o número de cesáreas eletivas); episiotomia; ética em ginecologia e obstetrícia; ética em tocoginecologia; remuneração do parto normal; valorização da profissão obstétrica. 
Os textos analisados foram veiculados pelos seguintes órgãos de classe da profissão médica: Associação de Ginecologia e Obstetrícia da Bahia (SOGIBA), Associação de Ginecologia e Obstetrícia do Estado de São Paulo (SOGESP), Associação de Ginecologistas e Obstetras de Minas Gerais (SOGIMIG), Associação de Ginecologia e Obstetrícia do Rio Grande do Sul (SOGIRGS), Conselho Federal de Medicina (CFM), Conselho Regional de Medicina do Distrito Federal (CRM-DF), Conselho Regional de Medicina do Estado de São Paulo (CREMESP), Conselho Regional de Medicina de Pernambuco (CREMEP), Conselho Regional de Medicina do Ceará (CREMEC) e Federação Brasileira das Associações de Ginecologia e Obstetrícia (FEBRASGO).

As publicações foram analisadas como práticas discursivas a partir do conceito foucaultiano de discurso (Foucault, 2003; 2002; 2001), entendidas como práticas coletivas, que implicam escolhas políticas, e que colocam em visibilidade certos enunciados sobre o tema e não outros. O suporte da pesquisa bibliográfica serviu como referencial teórico para a análise do discurso médico, especialmente a partir de estudos sobre a medicalização do corpo feminino e/ou do parto na perspectiva de gênero, de autores que dialogam com as áreas da saúde, da história e da antropologia.

\section{Violência obstétrica ou contra o obstetra? O discurso médico hegemônico no Brasil}

Em agosto de 2015, o Conselho Federal de Medicina (CFM) enviou carta à Revista Epoca no dia seguinte da publicação da reportagem "Parto com Respeito", que fez parte de uma campanha, sob o mesmo título, lançada três dias antes pela revista. A campanha teve como escopo trazer denúncias de mulheres que sofreram violência obstétrica, alertando sobre o assunto a partir dos resultados da pesquisa de referência, divulgada pela Fundação Perseu Abramo/SESC (Venturi; Godinho, 2010). A carta do CFM, com o "objetivo de defender os médicos" e

9 Cf. Parto com Respeito. Revista Época, Vida, edição de 03 de agosto de 2015. 
assinada pelo Presidente Carlos Vital Tavares Corrêa Lima, afirma que a Câmara Técnica de Ginecologia e Obstetrícia do Conselho tem tratado do assunto em busca de propostas para corrigir possíveis "distorções" da chamada violência obstétrica, "em suas diferentes nuances"; e defende a violência obstétrica como sendo a omissão do Estado na não garantia de "leitos e condições de atendimento necessários à realização de um parto seguro"10, parecendo ignorar a gravidade do problema identificado pela pesquisa de referência. A carta é categórica, ainda, ao afirmar que a imensa maioria dos 400 mil médicos, "mesmo em contextos absolutamente adversos" seguem as orientações do Código de Ética Médica, tratando todos os pacientes, especialmente gestantes e recém-nascidos, "com respeito à autonomia e com o melhor de sua técnica". O respeito à autonomia da paciente é um discurso frequente, assim como a referência ao comportamento uniforme dos médicos enquanto bons médicos a todos os pacientes. A violência ocorrida é atribuída à qualidade técnica e tecnológica da prática obstétrica de alguns médicos e à omissão do Estado na garantia de boas condições de trabalho.

O presidente da SOGESP, Jarbas Magalhães, em maio de 2015, em matéria publicada pela FEBRASGO $^{11}$, expressou a opinião da entidade sobre o assunto, condenando a violência obstétrica e afirmando ser dever oferecer às mulheres tratamento humanizado e de qualidade, além de zelar pela boa prática obstétrica e pela reputação dos ginecologistas e obstetras, "que, salvo exceções, têm postura ética e profissional elogiáveis". A preocupação com a reputação dos profissionais médicos no mesmo patamar que a preocupação com as mulheres, e a configuração da exceção em termos de comportamento, foi afirmada, ainda, como necessidade

${ }^{10}$ Cf. Violência Obstétrica: CFM envia carta à Revista Época defendendo os médicos.

Disponível

em: http://portal.cfm.org.br/index.php?option $=$ com content $\&$ view $=$ article\&id $=2564$ 9:2015-08-06-17-43-31\&catid=3, acesso em: 05 dez. 2015.

${ }^{11}$ Cf. Violência obstétrica: é necessário intervir com tratamento humanizado. Disponível em: http://www.febrasgo.org.br/site/?p=8819, acesso em: 28 nov. 2015. 
de "aprimoramento" para um nível de excelência na assistência $e$ de "civilidade e o respeito ao próximo" como "características essenciais a quem trabalha com gente, $e$ em especial com as mulheres". O texto recomenda uma série de condutas $e$ procedimentos à prática obstétrica, muitas delas de acordo com recomendações do Ministério da Saúde e da OMS. Mas o discurso com caráter de exceção é enfático, situando a violência obstétrica em nível comportamental:

Como em qualquer área, há em nosso meio, um ou outro mau profissional. Temos de identificá-los e puni-los de acordo com as normas vigentes e o Código de Ética Médica. Contudo, as mulheres brasileiras são testemunhas de que a regra da ginecologia e obstetrícia é o respeito e o atendimento qualificado.

Desconsiderando os dados revelados pela pesquisa de Venturi e Godinho (2010), na qual $25 \%$ das mulheres não são testemunhas dessa regra, finaliza, ainda, com os dizeres: "concluindo, entendemos também como VIOLÊNCIA CONTRA O OBSTETRA, a maneira superficial com que o tema tem sido abordado colocando o obstetra/ginecologista sempre como algoz" (grifos do autor).

O discurso da violência contra o obstetra, exatamente com esses termos, apareceu com uma certa relevância nas publicações. Em 2014, a SOGIMIG publicou uma matéria de capa em seu informativo ${ }^{12}$, sob o título Violência Obstétrica e contra o obstetra: a dor além do parto, inspirada na polêmica sobre o caso de Torres/RS. ${ }^{13} \mathrm{O}$ texto da médica Maria Inês Lima, presidente da

${ }^{12}$ Cf. Violência Obstétrica e contra o obstetra: a dor além do parto. Disponível em: http://sogimig.org.br/site/wp-content/uploads/Sogimig Maio.pdf, acesso em: 05 dez. 2015.

${ }^{13} \mathrm{Cf}$. O caso ocorrido na cidade de Torres, RS, em abril de 2014, provocou polêmica nas redes sociais e grupos organizados pela defesa da humanização do parto. Adelir Lemos de Goes, de 29 anos, sofreu intervenção judicial para a realização de uma cirurgia cesariana. O hospital Nossa Senhora dos Navegantes alegou que a mulher teria contrariado a decisão médica de indicação de cesárea 
SOGIMIG, é o único do boletim a mencionar os resultados da pesquisa de referência, de Venturi e Godinho (2010), sobre a violência obstétrica. Além de afirmar que a associação repudia esse tipo de violência, enfatiza que "as evidências e diretrizes" devem nortear a conduta médica "zelando e buscando o menor risco", ressalta que a SOGIMIG tem orientado seus associados quanto ao consentimento informado e os planos de parto. Mas esclarece que há uma "violência contra o obstetra" pela maneira como a mídia tem abordado esse assunto e que a associação defenderá o associado "sempre que for acusado injustamente". O texto, apesar de bastante ponderado, também assume um discurso abstrato sobre o obstetra $e$ a boa medicina: "Entendemos que o ginecologista e obstetra merece respeito, já que é um profissional que se dedica noite e dia a cuidar das suas pacientes, procurando praticar a boa medicina".

Roberto Magliano de Morais, membro da Câmara Técnica de Ginecologia e Obstetrícia da SOGIMIG, também inverte o lugar da vítima, em um texto do CFM, publicado em 2016, cujo título tem a mesma proposta, Violência obstétrica ou contra o obstetra?. ${ }^{14} \mathrm{O}$ texto apresenta duras críticas às gestóes governamentais do sistema de saúde obstétrico, denunciando um quadro de "equipes de atenção básica incompletas, muitas delas sem médicos, existem poucas e precárias maternidades, sempre lotadas e sucateadas, com falta de medicamentos e profissionais de saúde (...)", o que, juntamente com toda uma argumentação sobre os altos índices de mortalidade materna e sua relação com a precariedade no pré-natal, ele define como:

imediata, colocando em risco a vida da criança. Adelir e seu acompanhante alegaram não ter tido esclarecimentos suficientes quanto à indicação médica para a realização de cesariana e nem acesso ao exame de ultrassonografia realizado, decidindo arcar com a responsabilidade e aguardar o trabalho de parto em casa.

${ }^{14} \mathrm{Cf}$. Violência obstétrica ou contra o obstetra? Disponível em: http://portal.cfm.org.br/index.php?option $=$ com content\&view $=$ article\&id $=2600$ 9:2016-02-26-15-10-10\&catid=46:artigos\&Itemid=18, acesso em: 18 jan. 2016. 
a verdadeira face da violência obstétrica no país, praticada pelo governo contra as mulheres e injustamente transferida para o obstetra, o "soldado" descartável e desvalorizado, que fica no "front" de uma luta arriscada e muitas vezes inglória, pelo direito ao nascimento com dignidade $e$ segurança.

Ainda que os argumentos sobre a falta de estruturas $e$ recursos humanos em maternidades do país sejam contundentes, o texto não esclarece nada sobre violência obstétrica, apesar do título, e é motivado muito mais pelo incômodo de "tamanha mobilização" acerca do país estar "no topo do ranking de cesarianas no mundo (...). Para alguns, este procedimento é um exemplo do que se convencionou chamar de "violência obstétrica'", o que afirma logo no início do texto. Além de ignorar completamente a complexidade do tema da violência obstétrica, distorcendo seu conceito e relação com o parto cirúrgico, o texto parece debochar da seriedade da epidemia de cesarianas no Brasil. A argumentação desloca-se para a crítica ao filme $O$ renascimento do parto $^{15}$, afirma que "quem assistiu a este documentário saiu com a certeza de que a cesariana deve ser evitada a todo custo e que os médicos que a realizam não se preocupam com as gestantes", e discorre alguns parágrafos com seu incômodo sobre as doulas, cometendo equívocos a respeito do papel dessas profissionais e defesa delas pelo ativismo ${ }^{16}$.

\footnotetext{
15 O renascimento do parto (2013). Direção: Eduardo Chauvet.

${ }^{16}$ Segundo ele, em relação às doulas, o filme estaria "rasgando elogios à sua presença no local do parto em detrimento da do obstetra" (sic). O papel da doula é acompanhar a parturiente no trabalho de parto e no parto, dando apoio psicoemocional e físico, por meio de métodos e técnicas não farmacológicos (BRASIL, 2006). A função da doula, portanto, não é a de realizar partos e nem de intervir no trabalho da equipe médica. Os movimentos sociais não têm defendido sua atuação em substituição ao obstetra, mas, sim, como uma acompanhante. A proposta é que ela possa fazer parte da equipe de atenção ao parto nos hospitais, além do acompanhante já garantido por lei (Lei do Acompanhante), o que tem sido conquistado por meio da "Lei das Doulas" em algumas cidades brasileiras - fato também criticado por Magliano. A partir de uma série de perguntas sobre o perfil que define essa ocupação certificada pela
} 
O autor acusa a apropriação da "falácia da violência obstétrica" para "demonizar" os médicos, "os únicos legalmente habilitados para dar uma assistência completa ao parto", afirmando que o objetivo "por trás do discurso "naturalista' é fragilizar o papel do médico nas relações dentro do mercado de trabalho da área da saúde". Em outro momento, culpa as mulheres pela escolha do parto operatório:

\begin{abstract}
Muitos afirmam que as mulheres são induzidas pelos médicos a escolher o parto operatório, e esses profissionais são acusados de não explicar as consequências $e$ implicações dessa decisão para seu futuro reprodutivo. No entanto, não se reconhece que parcela considerável das pacientes opta por esta via, por sua conta e risco. Talvez essas mulheres tomem essa decisão por medo da dor, pelo receio de danos ao períneo e à sua sexualidade, ou pode ser que sejam influenciadas por parentes e pessoas próximas. Também é provável que a escolha tenha origem no temor, muitas vezes justificado, de parir numa maternidade brasileira.
\end{abstract}

O conselheiro não menciona o papel do obstetra sobre o que pode ser feito diante do medo da dor, por exemplo, e nem a respeito da informação e da decisão compartilhadas sobre os riscos da cirurgia. Assim como, não sugere também que o "temor" em parir em uma maternidade brasileira possa vir a partir desse modelo intervencionista que submete às mulheres à "cascata de procedimentos", e fazendo dessa uma experiência traumática no parto (Mold; Stein, 1986, apud Diniz, 2005:629). Além disso, pesquisa divulgada recentemente por Domingues et al. (2014) mostra a divergência entre a expectativa inicial das mulheres e o desfecho do parto, evidenciando que a proporção de cesariana é muito superior ao desejado pelas mulheres inicialmente. A justificativa da

Classificação Brasileira de Ocupações (CBO), o obstetra mostra, ainda, total desconhecimento dos critérios de formação das doulas e das regras para seu exercício. 
cesariana como prevenção de danos ao períneo e à sexualidade da mulher foi encontrada também no discurso médico em outra publicação ${ }^{17}$. No entanto, a pesquisa citada mostra que nenhuma mulher referiu a escolha da cesariana como forma de prevenção de lesões perineais (Domingues, et al., 2014). Assim como, as consequências negativas do parto vaginal para a vida sexual foram citadas por menos de $2 \%$ das mulheres, evidenciando que essa não é uma questão relevante para a decisão por cesariana por parte das mulheres.

Krikor Boyaciyan, conselheiro e coordenador da Câmara Técnica de Ginecologia e Obstetrícia do CREMESP, afirmou, em 2012, que a câmara repudia o termo violência obstétrica. Em texto publicado no Editorial do Jornal do CREMESP ${ }^{18}$, com o título Episiotomia não é violência obstétrica, afirma que:

Como princípio, a Medicina é uma profissão a serviço da saúde do ser humano e da coletividade e, nesse intuito, toda a atenção do médico visa o bem-estar dos mesmos. Dessa forma, o termo "violência" não se aplica ao exercício da Medicina e, portanto, "violência obstétrica" não configura qualquer ação médica propriamente dita. .

A generalização nesse texto, e nos citados anteriormente, de que "toda" atenção médica visa o bem-estar das pessoas, criando um ente transcendental "médico", remete à análise de Mota e Schraiber (2014) sobre o não reconhecimento da Medicina sobre o caráter histórico de suas práticas. Como afirmam os autores, é como se uma espécie de "a-historicidade" dos fins da Medicina justificasse suas práticas, "postulando-as como neutras quanto aos valores que regem suas ações" (Mota; Schraiber, 2014:1089). A última afirmação do parágrafo em destaque exemplifica bem isso,

\footnotetext{
${ }^{17} \mathrm{Cf}$. Cesárea a pedido: atender ou não? Disponível em http://www.cremesp.org.br/?siteAcao=Revista\&id=147, acesso em 30/11/2015.
}

18 Cf. Episiotomia não é violência obstétrica. Disponível em: http://www.cremesp.org.br/?siteAcao=Jornal\&id $=1969$, acesso em: 28 nov. 2015. 
por meio da noção de que é praticamente inconcebível que um ato médico, proveniente de uma formação médica, possa ser caracterizado como uma violência.

O texto de Boyaciyan é, na verdade, esclarecedor sobre não haver justificativas para uso rotineiro da episiotomia $e$ nem evidências que comprovem seus benefícios. O repúdio ao termo, no entanto, parece ser motivado pelo questionamento ao procedimento em si - a prática neutra pelo valor que rege sua ação, o que pode ser percebido pela afirmação de que a episiotomia "com indicação precisa" é uma prática obstétrica reconhecida, e que é dever do médico, segundo o Código de Ética Médica, "obter o consentimento livre e esclarecido" para sua realização. Contudo, o conselheiro parece desconhecer as pesquisas brasileiras (Aguiar, 2010; Santos; Shimo, 2008) que evidenciam a banalização do procedimento no país, e o fato de que o consentimento livre e esclarecido é descumprido frequentemente, sendo a paciente avisada na hora da realização de episiotomia ou, ainda, após sua realização.

"Se, durante o pré-natal, a gestante se mostrar absolutamente contrária à realização do procedimento, sob qualquer circunstância, o melhor é que seu parto seja assistido por um profissional que tenha exatamente o mesmo ponto de vista", defende Corintio Mariani Neto, médico ginecologista e obstetra, membro da Federação Brasileira das Associações de Ginecologia e Obstetrícia (Febrasgo), em entrevista ao jornal $O$ Estado de $S$. Paulo. ${ }^{19}$ A fala chama a atenção pelo fato de que, caso a mulher não concorde com os procedimentos $e$ a posição do médico obstetra, ela tenha que procurar outro profissional. Nesse sentido, a autonomia da mulher parece ser respeitada desde que não deseje algo diferente do obstetra, mesmo se assumir os riscos. Não é o profissional que deve respeitar sua decisão, ela é quem deverá procurar outro profissional.

${ }^{19}$ Cf. Grávida e ginecologista precisam conversar sobre episiotomia antes do parto. Matéria original do Jornal Estadão, 05 nov. 2016, veiculada no sítio eletrônico da FEBRASGO. Disponível em: http://www.febrasgo.org.br/site/?p=12926, acesso em: 12 nov. 2016. 
A reportagem, logo no início, faz menção à pesquisa Nascer no Brasil (Fiocruz), sobre a ocorrência da episiotomia em 53,5\% dos partos normais, em desacordo com a recomendação da Organização Mundial da Saúde (OMS) de que esse número seja em torno de $10 \%$, apresentando a posição do médico Mariani Neto que parece confirmar a recomendação: "propõe-se que seu uso seja restrito e seletivo para casos específicos". Apesar disso, assim como no texto de Boyaciyan, o obstetra recorre à retórica de que considerar seu uso adequado não pode ser considerado violência obstétrica:
A Febrasgo discorda frontalmente com a "demonização" da episiotomia e do profissional que a realiza de modo correto e seletivo, assim como não aceita em hipótese alguma que a sua prática adequada possa ser considerada "violência obstétrica".

É, portanto, mais um discurso que não contribui para o debate do conceito de violência obstétrica, nesse caso, associada à episiotomia e a seu uso irrestrito, como mostram os diversos estudos já citados, além de pesquisas não científicas realizadas com mulheres, via redes sociais, por militantes do movimento pela humanização do parto (Sena; Tesser, 2017). Essa "demonização" da episiotomia, portanto, está ligada à constatação de que, em muitos hospitais e maternidades brasileiras, públicas e privadas, o procedimento faz parte do protocolo comum. A própria reportagem se inicia com a frase "Episiotomia é um 'palavrão' pouco conhecido, mas um procedimento comum no país", mencionando a pesquisa da Fiocruz na sequência, mas cujo debate sobre esse problema é pouco enfrentado no discurso médico do entrevistado.

Em publicação sobre o tema da violência obstétrica, em maio de $2014^{20}$, citada anteriormente, a FEBRASGO menciona a

${ }^{20} \mathrm{Cf}$. Violência obstétrica: é necessário intervir com tratamento humanizado. Disponível em http://www.febrasgo.org.br/site/?p=8819, acesso em 28 nov. 2015. 
pesquisa da Fundação Perseu Abramo afirmando que ela "trouxe queixas quanto à opção de procedimentos dolorosos sem consentimento ou informação" (grifo meu). É interessante notar o quanto revela essa afirmação: a pesquisa trouxe "queixas", não dados. Outra publicação da federação ${ }^{21}$ sobre a violência obstétrica anuncia que será elaborada uma "cartilha do PARTO SEGURO" (grifos no original). ${ }^{22} \mathrm{O}$ artigo, apesar de afirmar objetivos de dar recomendações aos profissionais sobre o tema, pois "devem estar alertas e engajados nessa divulgação", faz ressalvas quanto aos entraves burocráticos e financeiros para montagem de equipes de plantão, afirmando, ainda, que a relação entre o médico e a paciente que o escolheu "é autônoma e livre da interferência dos planos de saúde". A responsabilidade pela violência obstétrica praticamente é deslocada do médico para a mulher: ela tem escolha para não sofrer o risco escolhendo seu médico na hora do parto. O texto é bastante revelador de um posicionamento conivente com as desigualdades de classe socioeconômica existentes no pensamento e na prática obstétrica brasileira. ${ }^{23} \mathrm{~A}$ princípio, a afirmação parece negligenciar o fato de essa escolha não ocorrer no atendimento público, e ocorrer no suplementar apenas por meio de remuneração à parte ao

\footnotetext{
${ }^{21}$ Cf. Confira as recomendações contra a violência obstétrica. Disponível em http://www.febrasgo.org.br/site/?p=10483, acesso em 28 nov. 2015.

${ }^{22}$ Observou-se nas publicações analisadas que vários médicos têm apontado esse termo, "parto seguro", como proposta de substituição do termo violência obstétrica.

${ }^{23}$ Há, ainda, a desigualdade de raça apontada por estudos feministas desde a década de 1970 para os quais, segundo Diniz (2001:213), "além da dimensão constitutiva do gênero implicada na descrição da fisiologia e da anatomia, há também, inscritos nestas descrições, atributos de classe e raça. Estes atributos justificariam uma assistência à saúde distinta por classe social, pois buscam explicar a fragilidade sexual e reprodutiva das mulheres brancas, abastadas $e$ sedentárias por um lado, e por outro, a noção de que o sofrimento fortalece as mulheres pobres e não-brancas, mais habituadas ao esforço $e$ à dor física". A pesquisa da Fundação Perseu Abramo, já citada, sobre a violência obstétrica também revela índices maiores de violência entre mulheres negras e pardas.
} 
obstetra. ${ }^{24}$ A desigualdade é afirmada pela classe médica em várias publicações, nas quais o discurso é reforçado em termos de que quem paga tem melhores chances do que quem não paga. Assim, os riscos de violência no parto, bem como a impossibilidade da escolha pela cesariana nos atendimentos públicos, são colocados como a verdadeira face da violência $e$ decorrente dos atrasos que caracterizariam a assistência oferecida pela rede pública.

Por fim, o presidente da SOGESP, Paulo Giraldo, em entrevista publicada ${ }^{25}$ pela Associação de Obstetrícia da Bahia (SOGIBA), e concedida durante o XXI Congresso Baiano de Ginecologia e Obstetrícia, realizado em Salvador, em outubro de 2016, fala sobre o posicionamento da associação em relação à violência obstétrica:

Primeiro nós estamos nos colocando muito claramente para dizer a toda população, não só de médicos, ginecologistas e obstetras, mas, também, para população leiga, que a maioria dos obstetras e ginecologistas não faz nenhuma violência. Muito pelo contrário, esse é um tema que tá sendo usado pela mídia, que gostou do tema, e está usando mais do que devia. Se você colocar numa balança, o obstetra faz muito mais coisas boas para mulher do que violência. Eu não concordo com esse termo "violência". Existem alguns grupos que tentam, por alguma razão, chamar atenção para a necessidade dos partos vaginais, que eu acho muito importante, porém, falar que existe sempre violência obstétrica não é uma verdade. Existem algumas situações, não só pelo obstetra, mas provavelmente pelas condições de trabalho, onde não tem alojamento adequado, enfermagem

\footnotetext{
${ }^{24}$ O Parecer CFM 39/2012 sobre a chamada disponibilidade obstétrica define que a cobrança de honorários, por médicos obstetras, pelo acompanhamento presencial em trabalho de parto, não configura dupla cobrança ou infração à ética médica.

25 "Não existe violência obstétrica em $100 \%$ dos atendimentos". Disponível em: http://sogiba1.tempsite.ws/noticias/nao-existe-violencia-obstetrica-em-100-dosatendimentos/, acesso em $10 \mathrm{dez} .2016$.
} 
adequada, não tem ambiente de sala de parto adequado, que a gente poderia talvez rotular como violência, mas é uma análise que precisa ser feita diferente do que estão querendo colocar. A SOGESP se coloca favorável a humanização do parto, se coloca favorável para que a mulher seja bem atendida e é totalmente contra a ideia de que existe uma violência obstétrica em $100 \%$ dos atendimentos, muito pelo contrário.

Nessa reportagem, o que não faltam são afirmações problemáticas, a começar pelo título, Não existe violência obstétrica em $100 \%$ dos atendimentos, que é sensacionalista e evidencia também a pretensão do órgão na divulgação sobre o assunto. Ainda que a matéria não seja assinada por um autor, foi publicada pelo órgão em questão, a SOGIBA.

As afirmações do presidente da SOGESP dispensam comentários, dado tudo o que foi discutido até agora. $\mathrm{O}$ tom superficial dos argumentos $e$ a indisponibilidade em enfrentar o tema é notório; as afirmações se contradizem, recaindo na forma de um discurso retórico sem que as questões acerca da violência obstétrica sejam discutidas. O ente médico transcendental também está presente na fala quando conclui que o médico faz muito mais coisas boas para a mulher do que violência. Assim como a referência ao incômodo da classe médica em relação aos questionamentos de certas práticas do modelo hegemônico, na medida em que vincula a violência ao total de atendimentos, quando afirma que a entidade é contrária à ideia de que exista violência em $100 \%$ dos partos. Além de, novamente, as condições de trabalho, aparecerem como justificativa para a violência obstétrica.

\section{Autonomia - para quem?}

$\mathrm{O}$ que o discurso desses médicos e entidades evidencia, sobretudo, especificamente sobre a problemática da violência obstétrica, é que a resistência para transformações técnicocientíficas a partir das evidências é maior do que as próprias 
evidências científicas, conforme já afirmou Diniz (2005). Há uma rejeição inicial em se aceitar que a violência existe simplesmente porque ela tem sido atrelada, pelos órgãos oficiais, pelas pesquisas e pelos movimentos sociais, não à exceção de comportamentos inadequados ou inabilidade profissional, mas a uma relação médico-paciente autoritária $e$ a procedimentos inadequados que fazem parte do protocolo comum. O paradigma desse modelo e a própria cultura médica obstétrica serem colocados em xeque parece ser o incômodo manifestado nesse discurso centrado na retórica técnico-científica a favor de uma obstetrícia a-histórica $e$ neutra, que não leva em consideração, como afirma Diniz, que

a técnica é política, e inscritos nos procedimentos de rotina - na imobilização, na indução das dores do parto e cortes desnecessários, na solidão, no desamparo - estão 'encarnadas' as relações sociais de desigualdade: de gênero, de classe, de raça, entre outras (Diniz, 2005:633).

O parto vaginal é defendido também retoricamente e, quase sempre, o discurso recai em sua qualificação como risco e como atraso ou falta de opção no atendimento da rede pública. $\mathrm{O}$ agendamento do parto cirúrgico tem sido identificado como uma das causas responsáveis pelo alto índice de cesarianas no país. No entanto, foram constatadas apenas defesas sobre esse tipo de procedimento. O termo "cesárea a pedido" tem sido utilizado como sinônimo de cesárea eletiva, na tentativa de transferir a responsabilidade à mulher por suas escolhas ${ }^{26}$, e apresentado sob

\footnotetext{
${ }^{26}$ Muitas razões têm sido apontadas sobre isso, entre elas, o grande número de intervenções desnecessárias e os maus tratos na prática de atenção ao parto que têm levado muitas mulheres a escolherem a cesariana como via de parto. Além disso, algumas pesquisas têm desconstruído o discurso de que a preferência da mulher brasileira é pela cesárea, mostrando que a maior porcentagem de mulheres tem como opção, no início da gestação, o parto vaginal, e que a porcentagem de cesarianas realizadas ao final é maior do que a média prevista de indicação médica, questionando o que se passa nesse percurso para que o desfecho se modifique (Diniz; Chacham, 2006; Faundes; Cecatti, 1998; Cecatti, 1991). A questão econômica e, principalmente, da conveniência para o
} 
o discurso do respeito à autonomia da paciente - isso foi identificado em quase todas as publicações analisadas que abordavam direta ou indiretamente esse tema. Mas serão essas escolhas sempre informadas ou consentidas com os devidos esclarecimentos? Essa é a pergunta importante a ser feita sempre. A pesquisa de Domingues et al. (2014), que teve como objetivo a reconstrução do processo de decisão pelo tipo de parto $e$ descrição dos fatores referidos pelas mulheres para a preferência do tipo de parto no início da gestação, assim como seu desfecho, evidencia que a informação sobre os tipos de parto apareceu em baixa proporção nos relatos das mulheres entrevistadas. Esse dado evidencia a pouca importância da informação para o processo de decisão das mulheres brasileiras, diferentemente do que é preconizado acerca da informação como fator de grande relevância para a participação das gestantes nos processos decisórios do parto e colocando em dúvida o cumprimento desse papel pelo obstetra. Assim como os riscos relacionados à cesariana foram pouco valorizados e foi maior a noção de segurança relacionada a esse tipo de parto entre mulheres que tiveram parto no setor privado - em que a porcentagem de cesáreas foi maior. Os autores afirmam, ainda, que

o maior relato de problemas de saúde no grupo atendido no setor privado, muitos deles sem qualquer relação com indicações reais de cesariana, não seria esperado, tendo em vista o melhor perfil socioeconômico dessa população, sugerindo uma banalização das indicações de cesariana (Domingues et al., 2014:10).

A autonomia parece ser mais apoiada pela classe médica hegemônica, portanto, quando a mulher opta por aquilo que a classe julga como sendo a boa prática obstétrica, quando não fere a autonomia do médico. Por exemplo, respeitando a mulher por desejar um parto cesáreo, mesmo sem quaisquer indicações

profissional da obstetrícia também são pontuados como fatores responsáveis pela cultura cesarista no Brasil (Domingues et al., 2014). 
médicas, mas sugerindo que a gestante deve procurar um profissional com seu ponto de vista quando ela não deseja que seja realizado em seu corpo um procedimento como a episiotomia. Há uma polícia discursiva sobre o que está "no verdadeiro" (Foucault, 2001) da boa prática obstétrica - os preceitos da cultura médica hegemônica, perpetuada por meio de suas práticas e da garantia de sua continuidade pela formação dos futuros médicos, funcionam como um dispositivo de verdade que ultrapassa evidências científicas, normas e recomendações de órgãos da saúde. As mulheres que optam por demarcar suas escolhas por outros modelos de assistência são infantilizadas $e$ hostilizadas. Nos casos de transferência de uma casa de parto ou de um parto domiciliar para os hospitais, os abusos verbais e as demoras no atendimento tendem a ser maiores, segundo constatou Diniz (2015). Assim como, os médicos que optam por outros modelos de assistência também são hostilizados, de acordo com o que a autora denomina "hierarquia interprofissional", em consonância com estudos realizados também em outros países acerca dessa constatação (Diniz, 2015:4).

As mulheres são infantilizadas também porque é reforçado nesse modelo que, para ficar segura, é preciso que a parturiente seja assistida por seu médico, o mesmo que a acompanhou no pré-natal, e não por uma equipe que esteja de plantão, reafirmando o imaginário simbólico de que o parto pertence ao médico e não à mulher. Essa postura contribui não apenas para o não protagonismo da mulher sobre seu corpo na experiência da gestação e do parto, como também para o alto índice de cesarianas eletivas. A possibilidade de agendamento do parto com um médico conhecido, ou seja, o mesmo que acompanhou o prénatal, foi o motivo mais referido entre mulheres que escolheram a cesariana como via de parto no setor privado, de acordo com o estudo de Domingues et al. (2014). Os autores sugerem que a forma de organização da assistência, que permite o agendamento, aliada a uma maior noção de segurança sobre o parto cesáreo pelas mulheres, nesse setor, são explicações possíveis para o maior índice de cesarianas na rede privada. 
Desse modo, o direito à escolha parece ser uma falácia, uma armadilha imposta às mulheres, que reside em um fato conceitual: não é a autonomia reprodutiva das mulheres que o discurso médico hegemônico afirma respeitar, mas a mulher enquanto vítima - de um atendimento obstétrico supostamente ultrapassado e com condições de trabalho inadequadas para o obstetra; de um sofrimento desnecessário do parto vaginal frente aos avanços farmacológicos e tecnológicos; da omissão do Estado de seu acesso ao padrão ouro da assistência obstétrica, a cesárea; e de sua condição impotente que necessita da tutela médica. A mulher enquanto transportadora do produto a ser esperado, com seu papel diminuído no binômio materno-fetal (Martin, 2006), necessitando do aval do médico para o exercício de sua autonomia, é uma noção extremamente atualizada nesses discursos.

Curiosamente, é a mesma centralidade da mulher enquanto vítima que move políticas públicas, pesquisas e movimentos sociais quando a questão é realmente sobre ser vítima do abuso de intervenções e da violência obstétrica. Mas nesse caso, o discurso médico hegemônico inverte a lógica, colocando como maiores vítimas os obstetras que, bem-intencionados e acima de qualquer demérito, estariam sendo alvo de injustiças ou das condições inadequadas de trabalho, impedidos, dessa maneira, de exercitar a boa prática. A profissão é o tempo todo reafirmada em termos de excelência e da exclusividade para uma assistência completa, em paralelo à defesa da violência como uma questão individual e comportamental de alguns médicos. Esse discurso evidencia também a atualização da defesa de uma profissão a partir da justificativa de procedimentos médicos, conforme identificou Arney (1982) a respeito da defesa da profissão por DeLee, no início do século $\mathrm{XX}$, a partir do modelo intervencionista. ${ }^{27}$ Uma profissão que tem se sentido ameaçada,

\footnotetext{
${ }^{27}$ Esse período é marcado por conflitos internos na ciência obstétrica em torno dos debates sobre as intervenções a partir do entendimento da "normalidade" dos partos. Mais do que isso: é a própria noção de intervenção como prática necessária à atenção obstétrica que está em jogo nesse momento. Arney (1982)
} 
conforme as palavras de Roberto Magliano de Morais, do CFM, em artigo já citado.

Esse sentimento de ameaça decorre do fato de que está havendo um movimento para que aconteçam mudanças nas práticas de assistência e proposições de novos modelos, ainda que muito pouco efetivo na prática. Mas decorre, também, de uma ameaça mais real e imediata para a classe médica, que é a de um novo problema no campo judicial. Os movimentos sociais de mulheres têm se organizado na tentativa de coibir abusos e dar nome à violência obstétrica cometida, denunciando procedimentos que, até então, eram realizados deliberadamente $e$ sem tantos problemas. Seja por meio de audiências públicas, seja pelo investimento nas redes sociais, as mulheres têm se pronunciado a respeito do tema. Por isso, a exasperação pela defesa do profissional, como vimos em quase todas as publicações. O investimento desse discurso na defesa da prática $e$ da profissão, ignorando a problemática da violência obstétrica em si, confirma a constatação de Diniz et al. sobre os efeitos de uma inversão sobre o que, de fato, seria o problema:

(...) a permanência, não regulada, de intervenções reconhecidamente inseguras e dolorosas, o que configura

argumenta que o que está em jogo nessa disputa é mais do que um debate técnico-científico, mas a tentativa de distinção entre o obstetra e o médico comum. DeLee era separatista, defendia o lugar exclusivo do obstetra no parto $e$ o "parto profilático", no qual era preciso antever a patologia intrínseca ao parto e atuar para que ela não ocorresse. Seu discurso afirmava a necessidade de sofisticar a arte obstétrica, criando saberes e técnicas que só o especialista bem treinado poderia acessar. Isso, não apenas para diferenciar a atuação dos obstetras frente às parteiras - que ainda atendiam aos partos normais - mas, $e$ talvez principalmente, frente aos médicos generalistas, que também atendiam partos. As evidências científicas dos benefícios das intervenções propostas por DeLee - a episiotomia, é um exemplo - por vezes, foram contestadas por outros obstetras americanos e europeus, indicando que se tratava mais de uma retórica do que de dados científicos de fato; ao que ele chegou a responder, em uma publicação no American Journal of Obstetrics and Gynecology, afirmando que as evidências seriam comprovadas futuramente atestando aquilo que ele afirmava (DeLEE, 1920). 
uma forma de violação de direitos 'nova', sendo a novidade o seu reconhecimento como problema e não sua ocorrência (Diniz et al., 2016:254).

Um padrão que foi identificado na análise do discurso médico hegemônico em praticamente todas as publicações analisadas é justamente um desvio no enfrentamento da problemática da violência obstétrica. Os conselhos, associações e federações, por meio de suas publicações, acabam por deslocar o tratamento das questões das práticas e evidências para a justificativa médica de casos específicos e para a defesa do profissional. Essa omissão da discussão sobre a realidade obstétrica, sobre dados revelados por pesquisas conduzidas seriamente dentro das melhores universidades $e$ instituições científicas do país, provoca um receio acerca do suporte dessas instituições que, teoricamente, têm como missão zelar pela prática médica a favor da sociedade e contribuir para a efetivação de políticas públicas que visem a melhoria da atenção à saúde. $\mathrm{O}$ tema da violência obstétrica é trazido em artigos, reportagens $e$ debates promovidos por esses órgãos; as pesquisas de referência algumas vezes são citadas, mas sem que haja enfrentamento da questão de fato. $\mathrm{O}$ discurso se resume a uma retórica em que a causalidade das problemáticas é deslocada e vista como empecilho à conformidade da profissão.

Em uma palestra realizada em junho de 2015, promovida pelo Conselho Regional de Medicina do Distrito Federal (CRM-DF) sobre o tema da violência obstétrica ${ }^{28}$, o médico Diaulas Costa chegou a afirmar que o Brasil não é o recordista em partos cesáreos, mas sim, a região do México, especificamente Monterrey, onde cerca de $90 \%$ das mulheres preferem o parto cesáreo. "O índice de cesariana da região de Monterrey é a maior do mundo. Muitas mulheres nem sabem o que é parto humanizado". A interpretação dos números apresentados a respeito de uma região

${ }^{28}$ Cf. Violência obstétrica é tema de palestra no CRM-DF. Disponível em http://www.crmdf.org.br/images/stories/publicacoes/boletim/boletim_junho.pdf, acesso em 10 dez. 2015. 
em relação à média geral do país, assim como a fonte da informação, não nos foi oferecida na reportagem, o que seria de grande contribuição, já que o último Relatório da Organização Mundial da Saúde, de 2010, aponta o Brasil no topo da lista de cesarianas realizadas no mundo mais uma vez. Qual seria a contribuição de se colocar Monterrey no lugar do Brasil nesse debate? Ainda que a região possa realmente ter índices alarmantes de cesáreas realizadas, a situação brasileira é preocupante e não se mostra enfrentada, de fato, nesses discursos.

A necessidade de mudanças na formação médica tem sido assinalada por vários autores (Diniz et al., 2016; Diniz et al., 2015; Hotimsky, 2007; Hotimsky; Schraiber, 2005) para superação da violência obstétrica, especialmente porque dentro do hospitalescola é onde, muitas vezes, ela acontece. Mas essa é outra questão intocável no discurso dos órgãos de classe. Trata-se de um modelo que perpetua a realização de procedimentos não consentidos, não informados, em nome da necessidade de treinamento de habilidades, e que configuram abusos que "permanecem normalizados por uma cultura institucional que não os reconhece como violações de direitos" (Diniz et al., 2016).

Por fim, gostaria de retomar a questão da preocupação com os danos no períneo e com a sexualidade da mulher, presente tanto na justificativa da episiotomia quanto do parto cirúrgico, em nome da vida sexual do casal. Sabemos, contudo, que esse pensamento, já defendido por DeLee em 1920, encontra eco na noção arraigada na cultura sexual e reprodutiva brasileira do mito do "afrouxamento vaginal", da vagina "usada", "laceada", decorrente de seu "uso", seja ele sexual ou reprodutivo, como bem identificou Diniz (2001). Não é do prazer feminino que se está falando, mas da preservação do prazer masculino. "A desvalorização sexual da vagina, e por decorrência da mulher, ou vice-versa, depois do parto, tem muitas analogias com a sua desvalorização depois do início da vida sexual" e se sustentaria tanto na cultura popular quanto na cultura técnica médica (Diniz, 2001:192). Vários são os autores que já discutiram a questão da sutura no períneo pós episiotomia, que, no Brasil, ainda é 
chamada de "ponto do marido", por ser realizado um ponto a mais para a preservação do prazer masculino no sexo (Diniz; Chacham, 2006).

\section{Considerações finais}

Podemos concluir que é nesse imutável e a-histórico fim de salvar as vidas de mãe e feto, atrelado a uma perspectiva patológica da gravidez e do parto, e na crença em uma tecnologia também a-histórica e vista apenas como meio, que estão muitos dos elementos para a compreensão do modelo obstétrico hegemônico. Os movimentos sociais por mudanças na assistência ao parto e nascimento esbarrariam já nessa primeira questão: a dificuldade de diálogo com a classe médica tradicional devido à grande resistência por mudanças. Para o discurso hegemônico, a autoridade médica é invisível e, portanto, não há o que ser questionado. Os argumentos envoltos por uma retórica de cientificidade, justificados pelo seu fim, não significam autoridade, mas, sim, verdade. Isso faz com que nem se discutam os procedimentos técnicos $e$ as práticas que são colocadas em xeque. Todo discurso contrário, questionador e militante é desqualificado.

Nesse sentido, tanto a prática quanto a formação médica tem se estabelecido mais como uma vocação de intervir $e$ prescrever do que de consultar e negociar. As escolhas da mulher não são respeitadas $e$ utiliza-se a autoridade científica para justificar tais condutas, pois apenas o médico saberia o que é melhor. Há, portanto, uma vontade de exclusão da mulher para que ela não participe das decisões, tornando-a objeto de intervenções e prescrições. Com isso, ocorre uma alienação da mulher com o seu corpo, sua fisiologia e sua experiência de gestação e parto. Esse lugar de autoridade da Medicina agencia uma subjetividade da mulher no parto que ocupa o lugar da incapacidade e da incompetência, contribuindo para o medo e a crença de que ela não é capaz de conduzir esse processo, entregando seu protagonismo nas mãos de quem, supostamente, tem o saber validado para tal. 
Mas é também sobre essa relação médico-paciente precária, estabelecida entre um sujeito que tem a autoridade legitimada do saber e outro que não sabe, baseada em uma lógica "colonialista", como afirmam Pimentel et al. (2014), que tem contribuído para o afastamento de muitas mulheres que desconfiam do modelo vigente, e que não enxergam nessa relação a possibilidade de terem seus corpos e suas escolhas respeitadas. Nesse sentido, a própria noção de risco, assim como de autonomia e sexualidade, é assumida por essas mulheres $e$ articula novas emergências discursivas e práticas. Para as autoras citadas, se na assistência hegemônica as assimetrias intersubjetivas do modelo biomédico, que inscreveu a gestação e o parto na esfera da patologia, são reforçadas, no modelo de assistência humanizada novas formas de subjetivação subvertem as relações de dominação, na medida em que a parturiente é vista como sujeito atuante no processo de tomada de decisão.

A sexualidade na esfera da experiência do parto também é outro ponto relevante. Ao mesmo tempo que a Ginecologia investiu no controle da sexualidade feminina (Rohden, 2000) e a Obstetrícia esforçou-se em removê-la da cena do parto (DavisFloyd, 1992), a dimensão sexual parece ser um eixo estruturante das técnicas médicas, que desconsideram os elementos subjetivos da mulher e tentam suprimir sua sexualidade ou atendem a convenções morais e patriarcais (Diniz, 2001), culminando em excesso de medicalização e na contribuição negativa sobre a experiência da mulher no domínio de seu corpo. Como afirma a autora, em pesquisa anterior (Diniz, 1997:56), a sexualidade talvez seja tão ou mais importante que as dimensões propriamente "reprodutivas". Por esse motivo, é proposto que a exploração do vínculo entre sexualidade e reprodução torne-se uma tarefa fundamental, não para "reprodutivizar" a sexualidade, "mas, ao contrário, de erotizar a reprodução, compreendendo o parto como uma função sexual normal das mulheres" (Diniz, 1997:56).

Por fim, chamo atenção para a questão do respeito à autonomia $e$ ao protagonismo da mulher. A questão não é ser a favor ou contra determinadas práticas do modelo hegemônico, 
impondo um ou outro modelo de assistência, mas do enfrentamento que se faz necessário sobre as questões pertinentes às problemáticas do atendimento obstétrico brasileiro para que as mulheres possam realmente fazer escolhas. Por isso, a favor do protagonismo da mulher, independentemente de sua escolha, este artigo tem um pressuposto político que é a necessidade de ampliação do acesso à informação e, principalmente, da formação da sociedade civil. Uma formação sobre o parto que aconteça desde o ensino escolar de jovens adolescentes até os diversos espaços não formais de educação e comunicação, como os museus, por exemplo (Palharini, 2015), e que trate do tema em suas esferas simbólicas, existenciais, sob as perspectivas histórica e de gênero, do campo da sexualidade e dos direitos sexuais $e$ reprodutivos das mulheres, para além da esfera biomédica.

\section{Referências bibliográficas}

AguiAR, J. M. de. Violência institucional em maternidades públicas: hostilidade ao invés de acolhimento como uma questão de gênero. Tese (Doutorado em Medicina Preventiva), Universidade de São Paulo, São Paulo, 2010.

ARney, W. R. Power and the profession of Obstetrics. Londres, The University of Chicago Press, 1982.

Cecatti, J.G.; Pires, H.M.; Goldemberg, P. Cesárea no Brasil - Um direito de opção? In: GALVÃo, L.; DIAZ J. Saúde Sexual e Reprodutiva no Brasil. São Paulo, Hucitec, 1998, p. 237-258.

DAVIS Floyd, Robbie. Birth as an American Rite of Passage. Berkeley; Los Angeles, University of California Press, 1992.

DELEE, J. B. The prophylactic forceps operation. American Journal of Obstetrics and Gynecology, n 1, 1920, pp.34-40.

DINIZ, S. G. et al. A vagina-escola: seminário interdisciplinar sobre violência contra a mulher no ensino das profissões de saúde. Interface: Comunicação, Saúde e Educação (Botucatu), vol. 20, n 56, mar 2016, pp.253-259. 
DINIZ, S. G. et alii. Abuse and disrespect in childbirth care as a public health issue in Brazil: origins, definitions, impacts on maternal health, and proposals for its prevention. Journal of Human Growth and Development, vol. 25, $\mathrm{n}^{\circ} \quad 3, \quad$ pp.377-384. DOI http://dx.doi.org/10.7322/jhgd.106080.

DINIZ, S. G. Gênero, saúde materna e o paradoxo perinatal. Revista Brasileira Crescimento e Desenvolvimento Humano, vol. 19, $\mathrm{n}^{\circ} 2$, 2009, pp.313-326.

. Humanização da assistência ao parto no Brasil: os muitos sentidos de um movimento. Ciência \& Saúde Coletiva, vol. 10, n 3 , 2005, pp.627-637.

. Entre a técnica e os direitos humanos: possibilidades e limites da humanização da assistência ao parto. Tese (Doutorado em Medicina Preventiva), Universidade de São Paulo, São Paulo, 2001.

. Assistência ao parto e relaçóes de gênero: elementos para uma releitura médico-social. Dissertação (Mestrado em Medicina), Universidade de São Paulo, São Paulo, 1997.

DiNIZ, S. G.; ChACHAM, A. S. O "corte por cima" e o "corte por baixo": o abuso de cesáreas e episiotomias em São Paulo. Questóes de Saúde Reprodutiva, vol.1, n¹, 2006, pp.80-91.

D'Oliveira, A. F. P. L.; Diniz, S. G; SchraiBER, L. B. Violence against women in health-care institutions: an emerging problem. The Lancet, vol. 359, n 9318, 2002, pp.1681-1685.

DOMINGUES, R. M. S. M. et alii. Processo de decisão pelo tipo de parto no Brasil: da preferência inicial das mulheres à via de parto final. Cadernos de Saúde Pública, vol. 30, 2014, pp.s101-s116.

FAUNDES, A.E., CeCATTI, J.G. Operação cesárea no brasil: incidência, tendência, causas, consequência e propostas da ação. Cadernos de Saúde Pública, vol. 7, n² 2, 1991, pp.150-173.

Ferreira Junior, A. R.; Barros, N. F. de. A humanização do parto no cenário de disputas da obstetrícia. Resenhas e Críticas bibliográficas. Physis Revista de Saúde Coletiva, Rio de Janeiro, vol. 22, nº 4, 2012, pp.1591-1593.

Foucault, M. A ordem do discurso. São Paulo, Edições Loyola, 2001. 

2002.

. A arqueologia do saber. Rio de Janeiro, Forense Universitaria, . Microfísica do poder. Rio de Janeiro, Edições Graal, 2003.

HOTIMSKY, S.N. A formação em obstetrícia: competência e cuidado na atenção ao parto. [Doutorado]. Faculdade de Medicina, Universidade de São Paulo,São Paulo, 2007.

HOTIMSKY, S.N.; AgUiAR, J.M.; VentURI, G. A Violência institucional no parto em maternidades brasileiras. In: VENTURI, Gustavo; GODINHO, Tatau (Orgs.). Mulheres brasileiras e gênero nos espaços público e privado: uma década de mudanças na opinião pública. São Paulo, Editora Fundação Perseu Abramo, Edições SESC SP, 2013.

HOTIMSKY, S.N.; SCHRAIBER, L.B. Humanização no contexto da formação em obstetrícia. Ciência \& Saúde Coletiva, 10(3), 2005, pp.639-49.

MAIA, M. B. Humanização do parto: política pública, comportamento organizacional e ethos profissional. Rio de Janeiro, Fiocruz, 2010.

MARTIN, E. A mulher no corpo: uma análise cultural da reprodução. Rio de Janeiro, Garamond, 2006.

MOLD, J.; STEIN, H. F. The cascade effect in the clinical care of patients. The New England Journal of Medicine, vol. 314, n 8, 1986, pp.512514.

MotA, A.; SCHRAiBER, L. B. Medicina sob as lentes da História: reflexões teórico-metodológicas. Ciência \& Saúde Coletiva, vol. 19, nº 4, 2014, pp.1085-1094.

PALHARINI, L. A. A história da atenção ao parto e nascimento: possibilidades dos museus como espaços de comunicação $e$ formação sobre o tema. Tese (Doutorado em Ensino de Ciências e Matemática), Universidade Estadual de Campinas, Campinas, SP, 2015.

PIMENTEL, C. et alii. Autonomia, risco e sexualidade: a humanização do parto como possibilidade de redefinições descoloniais acerca da noção de sujeito. REALIS, vol. 4, n 1 , jan-jun 2014.

ROHDEN, F. Uma ciência da diferença: sexo, contracepção e natalidade na medicina da mulher. Tese (Doutorado em Medicina Social), 
Instituto de Medicina Social, Universidade Federal do Rio de Janeiro, Rio de Janeiro, 2000.

SANTOS, J. de O.; ShIMO, A. K. K. Prática rotineira da episiotomia refletindo a desigualdade de poder entre profissionais de saúde $e$ mulheres. Escola Anna Nery, vol. 12, n 4, 2008, pp.645-650.

SENA, L. M.; TeSSER, C. D. Violência obstétrica no Brasil e o ciberativismo de mulheres mães: relato de duas experiências. Interface: Comunicação, Saúde e Educação, vol. 21, n 60, Botucatu, 2017 , pp.209-220. [http://www.scielo.br/scielo.php?script $=$ sci arttext\&pid $=S 1414$ 32832017000100209\&lng=en\&nrm=iso - acesso em: 10 nov. 2016]. http://dx.doi.org/10.1590/1807-57622015.0896.

SenAdo Federal. Relatório Final da Comissão Parlamentar Mista de Inquérito da Violência Contra as Mulheres. Subsecretaria de Apoio às Comissões Especiais e Parlamentares de Inquérito, 2013. [http://www.senado.gov.br/atividade/materia/getPDF.asp?t=130748\& - acesso em: 12 mar. 2016].

TESSER, C.D.n et alii. Violência obstétrica e prevenção quaternária: o que é e o que fazer. Revista Brasileira de Medicina da Família e Comunidade, vol. 10, n 35, 2015, pp.1-12.

TORNQUIST, Carmen Suzana. Armadilhas da Nova Era: natureza e maternidade no ideário da humanização do parto. Revista Estudos Feministas, vol.10, $\mathrm{n}^{\circ}$ 2, 2002, pp.483-492.

VentuRI, G.; GodinHo, T. (orgs.). Mulheres brasileiras e gênero nos espaços público e privado: uma década de mudanças na opinião pública. São Paulo, Editora Fundação Perseu Abramo, Edições SESC SP, 2013.

WORLD Health Organization (WHO). The prevention and elimination of disrespect and abuse during facility-based childbirth, 2014 [http://apps.who.int/iris/bitstream/10665/134588/1/WHO RHR 14.23 eng.pdf?ua =1\&ua=1 - acesso em: 12 nov. 2016.

Appropriate Technology for Birth. The Lancet, vol. 2, n 8452, 1985, pp.436-7. 


\section{Fontes}

BOYACIYAN, Krikor. Episiotomia não é violência obstétrica. Jornal do Cremesp. Editorial, edição 321, 12/2014, p. 2 [http://www.cremesp.org.br/?siteAcao=Jornal\&id=1969, acesso em: 28 nov. 2015].

CESÁREA a pedido: atender ou não? Debate. Revista Ser Médico, edição 28 , jul/ago/set/out 2004 [http://www.cremesp.org.br/?siteAcao $=$ Revista\&id $=147$ - acesso em 30 nov. 2015].

CONFIRA as recomendações contra a violência obstétrica. Notícias. Federação Brasileira das Associações de Ginecologia e Obstetrícia FEBRASGO, 11 de fevereiro de 2015 [http://www.febrasgo.org.br/site/?p=10483 - acesso em 28 nov. 2015].

MORAIS, Roberto Magliano de. Violência obstétrica ou contra o obstetra? Conselho Federal de Medicina, 26 fevereiro 2016 [http://portal.cfm.org.br/index.php?option $=$ com_content\&view $=$ articl e\&id=26009:2016-02-26-15-10-10\&catid=46:artigos\&Itemid =18 acesso em 18 jan. 2016].

PARTO com Respeito. Revista Época, Vida, edição de 03 de agosto de 2015.

POLlO, Luisa. Grávida e ginecologista precisam conversar sobre episiotomia antes do parto. Jornal $O$ Estado de $S$. Paulo. Notícias, 05/11/2016 [http://emais.estadao.com.br/noticias/bemestar,procedimento-que-arruinou-vida-sexual-de-bela-gil-por-um-anoe-indicado-em-alguns-casos, 10000086486 - acesso em: 12 nov. 2016].

VIOLÊNCIA Obstétrica: CFM envia carta à Revista Época defendendo os médicos. Conselho Federal de Medicina [http://portal.cfm.org.br/index.php?option $=$ com content\&view $=$ articl e\&id=25649:2015-08-06-17-43-31\&catid=3 - acesso em: $05 \mathrm{dez}$. 2015].

VIOLÊNCIA Obstétrica e contra o obstetra: a dor além do parto. Informativo. Associação Brasileira de Ginecologia e Obstetrícia de Minas Gerais - SOGIMIG, p. 7-11, maio/junho de 2014 
[http://sogimig.org.br/site/wp-content/uploads/Sogimig_Maio.pdf acesso em 05 dez. 2015].

VIOLÊNCIA obstétrica: é necessário intervir com tratamento humanizado. Notícias. Federação Brasileira das Associações de Ginecologia e Obstetrícia - FEBRASGO, 13 de maio de 2014 [http://www.febrasgo.org.br/site/?p=8819 - acesso em: 28 nov. 2015].

VIOLÊNCIA obstétrica é tema de palestra no CRM-DF (2015). Boletim Informativo CRM-DF. Conselho Regional de Medicina do Distrito Federal. Jun/2015 [http://www.crmdf.org.br/images/stories/publicacoes/boletim/boletim_j unho.pdf - acesso em: $10 \mathrm{dez}$. 2015]. 